\title{
Sensitivity of mixed-phase moderately deep convective clouds to parameterizations of ice formation - an ensemble perspective
}

\author{
Annette K. Miltenberger ${ }^{1}$ and Paul R. Field ${ }^{2,3}$ \\ ${ }^{1}$ Institute for Atmospheric Physics, Johannes Gutenberg University, Mainz, Germany \\ ${ }^{2}$ Institute of Climate and Atmospheric Science, School of Earth and Environment, \\ University of Leeds, Leeds, United Kingdom \\ ${ }^{3}$ Met Office, Exeter, United Kingdom
}

Correspondence: Annette K. Miltenberger (amiltenb@uni-mainz.de)

Received: 16 March 2020 - Discussion started: 8 June 2020

Revised: 5 February 2021 - Accepted: 5 February 2021 - Published: 10 March 2021

\begin{abstract}
The formation of ice in clouds is an important processes in mixed-phase and ice-phase clouds. Yet, the representation of ice formation in numerical models is highly uncertain. In the last decade, several new parameterizations for heterogeneous freezing have been proposed. However, it is currently unclear what the effect of choosing one parameterization over another is in the context of numerical weather prediction. We conducted high-resolution simulations $(\Delta x=250 \mathrm{~m})$ of moderately deep convective clouds (cloud top $\sim-18^{\circ} \mathrm{C}$ ) over the southwestern United Kingdom using several formulations of ice formation and compared the resulting changes in cloud field properties to the spread of an initial condition ensemble for the same case.

The strongest impact of altering the ice formation representation is found in the hydrometeor number concentration and mass mixing ratio profiles. While changes in accumulated precipitation are around $10 \%$, high precipitation rates (95th percentile) vary by $20 \%$. Using different ice formation representations changes the outgoing short-wave radiation by about $2.9 \mathrm{~W} \mathrm{~m}^{-2}$ averaged over daylight hours. The choice of a particular representation for ice formation always has a smaller impact then omitting heterogeneous ice formation completely. Excluding the representation of the HallettMossop process or altering the heterogeneous freezing parameterization has an impact of similar magnitude on most cloud macro- and microphysical variables with the exception of the frozen hydrometeor mass mixing ratios and number concentrations.

A comparison to the spread of cloud properties in a 10member high-resolution initial condition ensemble shows
\end{abstract}

that the sensitivity of hydrometeor profiles to the formulation of ice formation processes is larger than sensitivity to initial conditions. In particular, excluding the Hallett-Mossop representation results in profiles clearly different from any in the ensemble. In contrast, the ensemble spread clearly exceeds the changes introduced by using different ice formation representations in accumulated precipitation, precipitation rates, condensed water path, cloud fraction, and outgoing radiation fluxes.

Copyright statement. The works published in this journal are distributed under the Creative Commons Attribution 4.0 License. This licence does not affect the Crown copyright work, which is reusable under the Open Government Licence (OGL). The Creative Commons Attribution 4.0 License and the OGL are interoperable and do not conflict with, reduce or limit each other. (C) Crown copyright 2021.

\section{Introduction}

Clouds consisting of a mixture of liquid and solid particles (mixed-phase) clouds play an important role in weather and climate at all latitudes. For example, observational data suggest that a significant fraction of surface precipitation form in mixed-phase clouds (e.g. Field and Heymsfield, 2015). It has also been demonstrated that the representation of cloud glaciation in global climate models has a substantial impact on the simulated mean climate state (e.g. McCoy et al., 2016). Despite this importance of mixed-phase clouds, for 
predicting weather and climate, the physical understanding of the underlying processes, most importantly ice formation, is very limited. Unsurprisingly, the representation of mixedphase clouds is one key source of uncertainty in weather and climate models (e.g. Korolev et al., 2017).

The formation of ice particles in the atmosphere has received particular attention over the last decades. Although the underlying physics of ice nucleation are still not understood, data from laboratory and field measurements have been used to suggest a number of new parameterizations that relate the aerosol population and environmental temperature to the number of nucleating ice crystals (e.g. DeMott et al., 2010, 2015; Niemand et al., 2012; Atkinson et al., 2013; Wilson et al., 2015). These new formulations gradually replace older formulations used in numerical weather prediction models (e.g. Cooper, 1986; Meyers et al., 1992). While it has been demonstrated that more sophisticated formulations of heterogeneous freezing, in particular its dependency on the aerosol population, are beneficial for predicting certain cloud types (e.g. Klein et al., 2009; Vergara-Temprado et al., 2018), it is not clear what the impact of choosing one parameterization over another parameterization is. A recent publication by Hawker et al. (2020) suggested that the increase in the ice-nucleating particle (INP) number concentration per unit decrease in temperature, i.e. the slope of the parameterization, plays a key role in determining the impact of a specific parameterization on the simulated tropical deep convective cloud field.

In addition to heterogeneous and homogeneous freezing of solution droplets, new ice particles can also be formed by so-called secondary ice formation processes, of which the Hallett-Mossop process is the most well known (e.g. Field et al., 2017). Although secondary ice formation seems to be crucial to explain the observed ice crystal number concentration in many clouds, its representation in numerical models is highly uncertain, and its importance for determining cloud properties is still debated (e.g. Field et al., 2017). Formulations for processes other than the Hallett-Mossop processes have only become available recently (e.g. Sullivan et al., 2018).

Here, we investigate the impact of using different heterogeneous freezing parameterizations and including a representation of the Hallett-Mossop process on the simulated evolution of moderately deep convective clouds (cloudtop temperature around $-18^{\circ} \mathrm{C}$ ) over the United Kingdom, thereby expanding the study of Hawker et al. (2020) to a different cloud regime.

The standard approach to estimate the impact of altered cloud microphysical parameterizations is to conduct sensitivity experiments. The differences between the various experiments are interpreted as the impact of the parameterization change. However, to assess the importance of the identified sensitivity in the context of model development and improvements for numerical weather prediction, it is vital to compare the sensitivity to changes in one parameterization to the uncertainty of the prediction due to other deficiencies in the model formulation and the overall predictability of the considered case. The latter is particularly important for convective situations with a small intrinsic predictability, as any small perturbation may rapidly amplify under these conditions (e.g. Hohenegger and Schär, 2007; Dey et al., 2014). The relevance of taking the predictability of different situations into account when assessing the sensitivity to parameterization changes is gaining increasing attention (e.g. Wang et al., 2012; Posselt et al., 2019). Quantifying the relative importance of initial condition uncertainty and uncertainty due to the model formulation is important for identifying priorities in future model development and justifying investment in more complex model formulations for operational weather forecasting centres. To address this issue, we place the sensitivity experiments in the context of a high-resolution initial condition ensemble.

The two key research questions addressed in the paper are as follows:

- How sensitive are mixed-phase convective clouds with cloud-top temperatures around $-18^{\circ} \mathrm{C}$ to the parameterization of ice formation (heterogeneous freezing and Hallett-Mossop process)?

- How does the sensitivity to different descriptions of ice formation compare to typical initial condition uncertainty for day-1 forecasts?

The paper starts with a short introduction to the investigated case (Sect. 1) and the model framework used for the simulations (Sect. 2). The results from the sensitivity experiments are presented in Sect. 3 and placed in the context of the ensemble simulations in Sect. 4. Finally, the key findings are summarized and discussed in Sect. 5.

\section{Model and data}

Simulations were conducted for the 3 August 2013 case from the COnvective Precipitation Experiment (COPE) campaign (Blyth et al., 2015; Leon et al., 2016; Miltenberger et al., 2018a). The campaign took place over the South West Peninsula of the British Isles and probed convective clouds forming along converging sea-breeze fronts. We use the Unified Model (UM) vn10.3 with the Cloud Aerosol Interacting Microphysics Module (CASIM). The model set-up is identical to that described in Miltenberger et al. (2018a, b); key points of the set-up are summarized here, and more detailed information is included in Appendix A. A regional nest with a grid spacing of $1 \mathrm{~km}$ resolution is nested in the global simulations, which in turn drives a second nest with a grid spacing of $250 \mathrm{~m}$. Only data from the innermost nest are used here. The initial and lateral boundary conditions for the $1 \mathrm{~km}$ nest are derived from the operational control run and nine members of the global operational ensemble forecast from the 
Met Office (MOGREPS; Bowler et al., 2008), which represent the anticipated spread of moisture and moist energy convergence over the region of interest (see also Miltenberger et al., 2018b). The aerosol environment is represented by using a constant profile for initial and boundary conditions, which has been derived from aircraft observation ("standard" aerosol scenario in Miltenberger et al., 2018a), and by allowing for advection of aerosols in the domain. The aerosol profile is specified in terms of aerosol mass and number concentration of three soluble and one insoluble aerosol modes. The cloud microphysics are represented by the CASIM scheme, which is a two-moment scheme with five hydrometeor categories. In the configuration used here, aerosol properties influence cloud droplet and ice crystal formation, but the cloud microphysical processes do not alter the aerosol properties ("passive" mode in Miltenberger et al., 2018a).

Substantial parametric and systematic structural uncertainty resides in the model representation of cloud microphysical processes, in particular with regard to ice formation processes. Several heterogeneous freezing parameterizations, which differ in the parameters used and the form of the temperature dependence of ice formation (e.g. Hawker et al., 2020), have been suggested over the last decade. In order to investigate the implications of choosing specific schemes for numerical weather prediction, a set of new simulations has been conducted: seven simulations with different heterogeneous freezing parameterizations ("FSENS"), one simulation omitting the parameterization of the Hallett-Mossop process ("NoHM"), and one omitting all ice-phase processes ("WARM"). The HallettMossop process describes the generation of so-called secondary ice crystals during riming of snow and graupel, and a fixed number of additional small ice crystals are generated per gram of accumulated rime in the model. This number is temperature dependent with a maximum at an ambient temperature of $-5^{\circ} \mathrm{C}$ and decay to zero at temperatures of -3 and $-8^{\circ} \mathrm{C}$ respectively. Initial and lateral boundary conditions for these sensitivity experiments are derived from the operational global control run. For the FSENS experiments, we used the heterogeneous freezing parameterizations by Meyers et al. (1992), M92; Atkinson et al. (2013), A13; DeMott et al. (2010), DM10; DeMott et al. (2015), DM15; and Niemand et al. (2012), N12. The DM10 parameterization is used in the "NoHM" simulation. The Meyers et al. (1992) parameterization predicts the number of ice crystals based only on the temperature at the location of interest and is, therefore, conceptually the "simplest" parameterization used here. The DeMott et al. $(2010,2015)$ parameterization considers, in addition to the temperature, the aerosol number concentration of particles with diameters larger than $0.5 \mu \mathrm{m}$. Thus, this parameterization provides an empirical link to the number of INPs that are expected to be present given the aerosol concentration at the location of interest. Finally, the parameterizations by Niemand et al. (2012) and Atkinson et al. (2013) are based on a temperature-dependent parame- terization of the number of active sites per unit surface area of dust aerosol. This number density of actives sites is then convolved with the total surface aerosol of dust aerosol to again obtain the number of INPs. Therefore, the different representations of ice nucleation reflect different levels of detail in the representation of heterogeneous ice formation.

When the number of INPs as a function of temperature is considered for a fixed aerosol concentration, Hawker et al. (2020) showed that the important controlling factors are the slope of the temperature dependence (i.e. $\frac{\mathrm{dINP}}{\mathrm{d} T}$ ) and the temperature at which the INP number concentration reaches the dust number concentration (i.e. the maximum possible value). The combined effect of these differences results in the Meyers et al. (1992) parameterization having the highest INP concentration at temperatures warmer than about $-18^{\circ} \mathrm{C}$ and the Atkinson et al. (2013) parameterization having the lowest INP concentration. At temperatures colder than about $-18^{\circ} \mathrm{C}$, the Atkinson et al. (2013) parameterization has the highest and the DeMott et al. (2010) parameterization has the lowest INP number concentrations. In addition to the sensitivity experiments with different heterogeneous freezing parameterizations, two simulations with prefactors of 10 and 0.1 for the DM10 parameterization are included, which represent high- and low-INP regimes induced by changes in aerosol concentration. The simulation with the DM10 parameterization is identical to the "control" simulation in Miltenberger et al. (2018b) and is referred to as the "baseline" simulation in the following.

The baseline simulation with the DM10 parameterization has been compared to observational data in Miltenberger et al. (2018a). In that paper, we found a good agreement of the thermodynamic structure of the simulated atmosphere and the 2-hourly radiosondings from Davidstow: in particular, a stable layer at the height of about $5-6 \mathrm{~km}$, which determines the maximum cloud-top depth, is found in the model at approximately the same altitude $( \pm 50 \mathrm{hPa})$ and with the comparable stability. Moreover, the altitude of the $0^{\circ} \mathrm{C}$ isotherm and the lifting condensation level were found to deviate by less than $250 \mathrm{~m}$ from the observed position. In the sensitivity experiments discussed here, no systematic difference in the thermodynamic structure is found (not shown). Additionally, Miltenberger et al. (2018a) compared the vertical velocity dependence of the cloud droplet number concentration at cloud base in the model to in situ observations taken with the BAe 146. Qualitatively, the dependence of the cloud droplet number concentration on the cloud-base updraught velocity is very similar in the model and observations, but absolute values are overestimated by about $30 \%$ in the model. A qualitative comparison of the variation of the cloud droplet number concentration with altitude indicates a stronger decrease in the cloud droplet number concentration with altitude in the observations. This is most likely due to the aerosol treatment in the "passive" aerosol mode of CASIM also used here, as simulations with a fully interactive aerosol version of CASIM showed improvements. Com- 
parison to ice-phase particle concentrations is difficult due to the specific sampling strategy in rising turrets, which can suffer from bias (Field and Furtado, 2016) and is not easily mimicked from the modelling data. To gain further insight into the representation of the cloud field as a whole, 3-D radar data were utilized in Miltenberger et al. (2018a): the mean and maximum cloud-top height, measured by the maximum altitude of the $18 \mathrm{dBZ}$ contour, compared well between the model and radar (differences $<500 \mathrm{~m}$ ). As there is little change in the mean or maximum cloud-top height in the sensitivity experiment, determined by the maximum altitude of cloud condensate (radar reflectivity data are not available for the sensitivity experiments), this comparison is not expected to deteriorate. Only the WARM simulation shows systematically lower mean cloud-top heights, which will likely result in a somewhat less favourable comparison to radar observations. In addition, the time series of domainaverage surface precipitation in the simulations was compared to the radar-derived surface rainfall rates (Radarnet IV rainfall retrieval; Harrison et al., 2009). The baseline model simulation was found to underestimate surface precipitation in the morning hours and the early evening by about $80 \%$, but the temporal structure and the main precipitation period (precipitation rate within 10\%) are both captured well. The same comparison including the sensitivity experiments analysed in this paper is shown in Fig. S1 in the Supplement. Again, the sensitivity experiments show neither a systematically enhanced nor diminished performance. Only the reduced precipitation rates in the WARM experiments seem less comparable to the observations. In summary, we have demonstrated that the baseline simulation successfully captures many features of the observed cloud and precipitation evolution, the thermodynamic conditions, and cloud microphysical parameters. This conclusion also holds for all sensitivity experiments here, with the exception of the WARM case. A more detailed comparison with in situ observations of ice phase or the 3-D radar reflectivity structure would be interesting, but this is beyond the scope of the present paper. Accordingly, the set-up provides a meaningful framework for the sensitivity analysis presented here.

\section{Sensitivity of cloud field properties to the representation of ice formation}

Varying the representation of primary and/or secondary ice formation has a direct impact on the number of ice crystals produced at a specific temperature; hence, the ice crystal number concentrations (ICNCs) vary between the different experiments. Despite a multitude of other processes altering ICNCs in a complex cloud field, systematic variations in the average ICNC profile appear in the different experiments (Fig. 1c). The profiles used here are average in-cloud profiles over the time period from 10:00 to 19:00 UTC. Differences are largest towards cloud top, with a spread of about 1 or- der of magnitude at $5 \mathrm{~km}$ altitude. Cloud bases are located at roughly $1 \mathrm{~km}$ altitude, cloud tops are located at $5.5-6 \mathrm{~km}$ altitude, and the $0{ }^{\circ} \mathrm{C}$ level is found at around $2.6 \mathrm{~km}$ altitude (Miltenberger et al., 2018a). In the altitude range where the Hallett-Mossop processes is active (i.e. $3-4 \mathrm{~km}$ altitude corresponding to roughly -3 to $-8^{\circ} \mathrm{C}$ ), ICNCs vary by about a factor 2 between the FSENS experiments, whereas ICNCs in the NoHM run are about 1.5 orders of magnitude smaller than in any FSENS experiment. Despite this clear signal of the Hallett-Mossop process in the 3-4 km altitude range, ICNCs towards cloud top reach similar values as in the FSENS experiments.

The differences in ICNCs can impact the occurrence of other hydrometeor species via various cloud microphysical processes (Fig. 1): Snow crystal concentrations vary by up to a factor 2 between the different FSENS experiments and are a factor of 5 lower in the NoHM experiment. In contrast to the signal in the ICNC, the imprint of the HallettMossop processes is consistent throughout the cloud layer. Interestingly, the variation in the graupel number concentration is the largest of all frozen hydrometeor types. Again, the NoHM simulation displays the lowest number concentration. Altering the representation of ice formation also impacts the number concentration of liquid hydrometeors, particularly in the upper cloud parts: while the cloud droplet number concentration (CDNC) in the WARM simulation is almost constant with altitude, it is significantly reduced in the FSENS and NoHM experiments above about $3 \mathrm{~km}$. This is likely a consequence of freezing and collection by ice, snow, and graupel particles. Interestingly, FSENS experiments with a high ICNC above $5 \mathrm{~km}$ have a low CDNC and vice-versa, implying a major impact of cloud droplet freezing. Variations in rain number concentrations are somewhat smaller than in the CDNC. The profiles from the NoHM experiment feature roughly in the middle of the FSENS experiments for both cloud droplet and rain drop number concentration, i.e. the main impact of the Hallett-Mossop process is limited to frozen hydrometeor species in our simulations. If, instead of the mean number concentration, the 95th percentile is considered, the general behaviour is very similar to that just discussed for the mean profiles (Fig. S2). The one outstanding differences is a much larger ICNC in the simulation with enhanced INP concentrations ("HighDM"). This suggests that while higher INP concentrations result in an enhanced ice crystal formation, as is to be expected, the impact on the mean ICNC is much smaller due to the depletion of ice crystals by other microphysical processes, such as the conversion to snow or graupel.

The average profiles of hydrometeor mass mixing ratios essentially mimic the sensitivities just discussed for the hydrometeor number concentrations (Fig. 2). Ice, snow, and graupel mass mixing ratios are consistently lower in the NoHM experiment than in all other experiments. Differences in ice, cloud droplet, and rain drop mass mixing ratios occur mainly in the upper part of the clouds (above $\sim 3.5 \mathrm{~km}$ ), 
(a)

(b)
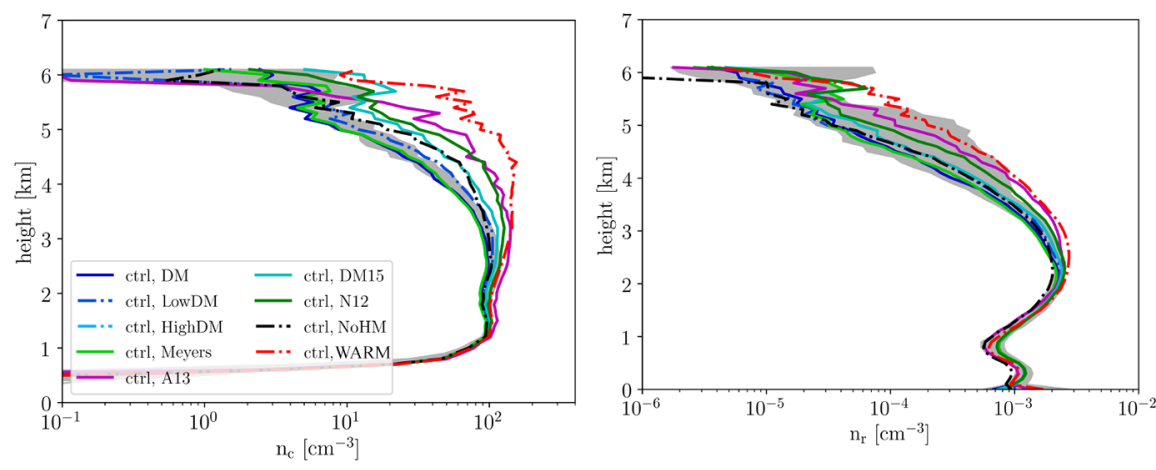

(c)

(d)

(e)
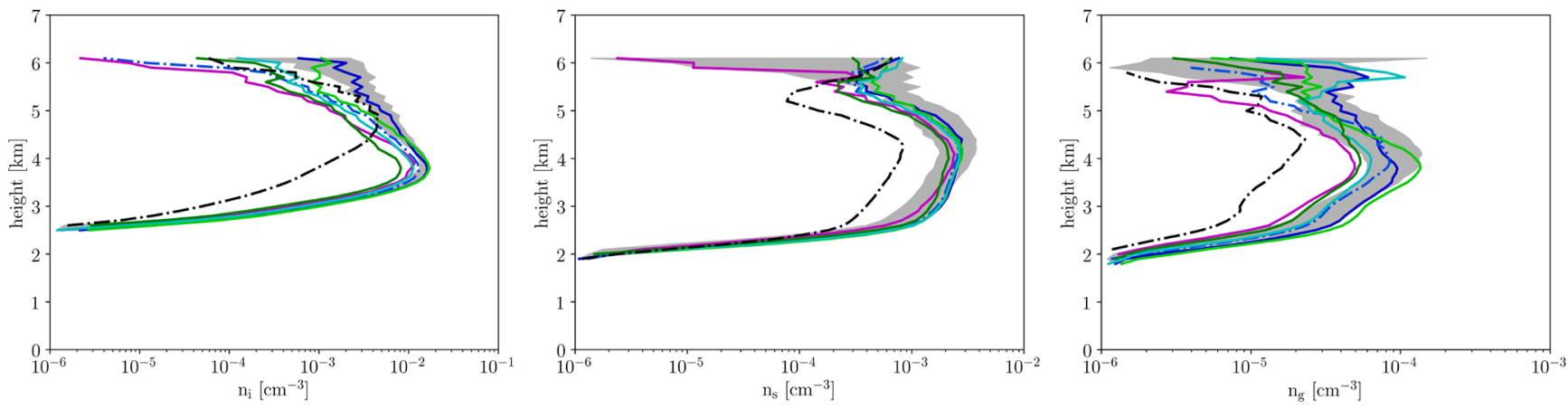

Figure 1. Average profiles of in-cloud number concentrations of (a) cloud droplets, (b) rain drops, (c) ice crystals, (d) snow, and (e) graupel. Different coloured lines show the profiles from simulations with different heterogeneous freezing parameterizations, different INP number concentrations, without a parameterization of the Hallett-Mossop process, and with warm cloud microphysics only (colours according to legend). The grey shading shows the spread of the average profiles in the 10-member high-resolution ensemble with the DeMott et al. (2010) heterogeneous freezing parameterization and a representation of the Hallett-Mossop process. The $0{ }^{\circ} \mathrm{C}$ level is located at about $2.6 \mathrm{~km}$ altitude.

whereas variation in snow (graupel) mass mixing ratio are small (large) throughout the entire cloud layer.

Different representations of ice formation clearly impact the cloud microphysical structure of the moderately deep convective clouds from COPE. We now investigate how these changes impact larger-scale features of the cloud field, such as the structure of the surface precipitation field, accumulated precipitation, and top-of-the-atmosphere radiation fluxes. The instantaneous precipitation rate at 14:00 UTC, e.g. close to the time of most intense precipitation, is shown in Fig. 3. In all simulations, a line of organized convection extends roughly along the centreline of the peninsula (i.e. WSW-ENE). Overall, the structure of the precipitation field is similar in terms of area covered, number of cells, and peak intensity of the cells. The variability between the different sensitivity experiments is comparable to the difference between different members of the initial condition ensemble using the DeMott et al. (2010) parameterization (Fig. S3). For a more quantitative analysis, we consider accumulated surface precipitation and the precipitation rate distribution. Accumulated surface precipitation varies by about $8 \%$ be- tween FSENS experiments (Fig. 4a). While omitting secondary ice formation leads to an increase in accumulated precipitation of about $\sim 6 \%$ relative to the baseline simulation, omitting all ice formation results in a reduction of accumulated precipitation by about $\sim 21 \%$. Understanding the changes in accumulated precipitation from the differences in the cloud microphysical composition of the clouds is not straightforward; therefore, we choose to investigate the cloud condensate budget as suggested, for example, by Khain (2009) and Miltenberger et al. (2018a). In this analysis framework, the changes in cloud condensate in the domain are analysed: cloud condensate can be generated in regions of lifting and can then be converted to surface precipitation, or it can be depleted by evaporation and sublimation (condensate loss). In addition, the total cloud condensate content in the domain can be influenced by advective fluxes, but Miltenberger et al. (2018a) showed that this has a negligible impact for the present case. Condensate generation is strongly controlled by thermodynamics and dynamics (i.e. the amount of lifting in the domain and the vertical temperature structure) and to a smaller degree by deposition growth in mixed- 
(a)

(b)
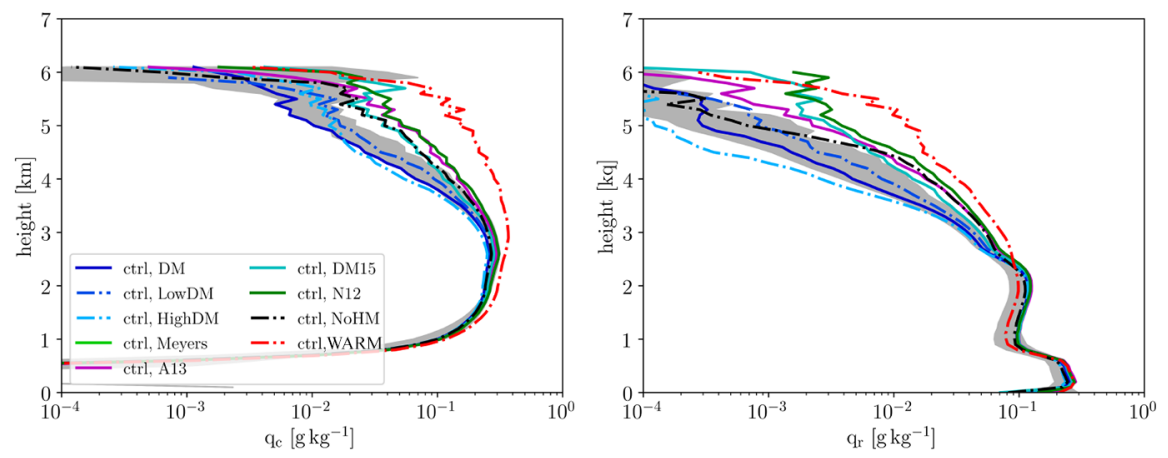

(c)

(d)

(e)
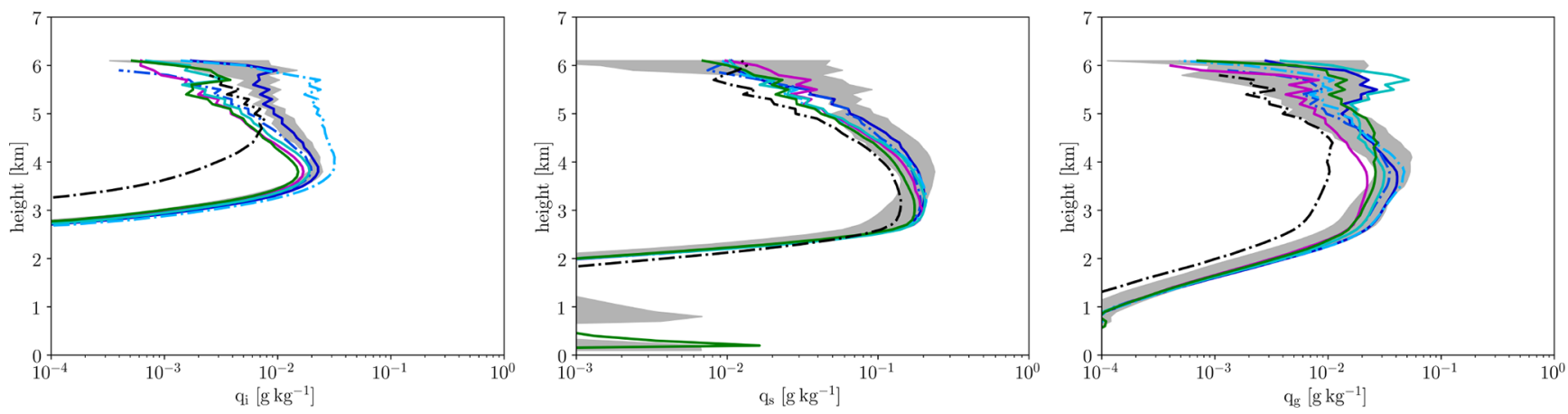

Figure 2. Same as Fig. 1 but for hydrometeor mass mixing ratios.

and ice-phase clouds (the UM employs a saturation adjustment scheme). The partitioning between condensate being converted to precipitation and condensate evaporating (condensate loss) is much more strongly influenced by cloud microphysical processes. To investigate changes in precipitation between simulations, the changes in condensate generation and condensate loss can provide insight into the driving processes. Differences in accumulated condensate generation $(\Delta G)$ and condensate loss $(\Delta L)$ are calculated relative to the baseline simulation, i.e. using DM10. In the scatterplot of $\Delta G$ against $\Delta L$, the FSENS and NoHM experiments cluster on the one-to-one line (Fig. 5a). Simulations falling exactly on the one-to-one line in this diagram have the same surface precipitation, as change in condensate generation and condensate loss compensate for each other. The red (blue) dashed lines in Fig. 5a indicate the distance away from the one-to-one line that correspond to a decrease (increase) of accumulated precipitation by $0.5 \%, 5 \%$, and $10 \%$. Except for the WARM simulation, changes in accumulated precipitation are smaller than about $5 \%$, as already shown in Fig. 4a. Relative changes in $G$ and $L$ are $\leq 2 \%$ for FSENS experiments. In the NoHM experiments, changes to $G$ and $L$ are larger ( $\sim 4 \%$ ), but they balance each other out, resulting in a small net change in accumulated precipitation. Combined with the much larger changes in the cloud microphysical structure, this implies that changes in precipitation formation via a specific cloud microphysical pathways are compensated for to a large degree by changes in other pathways, resulting in an overall similar integrated precipitation production. The only experiment displaying a different behaviour is the WARM experiment: while condensate generation decreases by $\sim 5 \%$, condensate loss only decreases by $\sim 0.1 \%$. Hence, the reduction in accumulated precipitation compared with the baseline simulation is the result of much less condensate being produced in the WARM experiment. If assuming the vertical displacement of parcels does not change between simulations and any produced supersaturation is depleted by condensate formation, this is consistent with the lower saturation vapour pressure over ice than over water. However, without supporting evidence, this remains a hypothesis. Further, a negative $\Delta G$ and no change in $\Delta L$ implies that the precipitation efficiency in the WARM experiment is larger than in any experiment with ice microphysics. Precipitation efficiency is defined here as the ratio of the time- and domain-integrated precipitation rate to the condensation and deposition rate. This response is contrary to what has been reported for isolated orographic clouds (e.g. Barstad et al., 2007; Miltenberger, 2014) and the larger precipitation efficiency for more rapidly glaciating clouds in high-INP environments found in global climate model simulations (e.g. 
Lohmann and Hoose, 2009). However, a reduction in precipitation efficiency with an increased cloud glaciation has been also found by Levin et al. (2005) for convective clouds in the Mediterranean.

Similar to the accumulated precipitation, the precipitation rate distribution displays only a weak sensitivity to the parameterization used for the representation of primary ice formation (Fig. 4b). Again, the only experiment with a substantially different behaviour is the WARM experiment, which displays a shift towards more intense precipitation: high precipitation rates $\left(\geq 20 \mathrm{~mm} \mathrm{~h}^{-1}\right)$ are more frequent, whereas medium rain rates between 1 and $10 \mathrm{~mm} \mathrm{~h}^{-1}$ are about $10 \%$ less frequent. Very high precipitation rates (i.e. the 95th and 99th percentile) display the largest changes. The 95th percentile varies by about $20 \%$ between the FSENS experiments and increases by $50 \%$ in the WARM experiment compared with the mean of the FSENS experiments (Fig. S3).

The condensed water path and the cloud fraction are other important properties of the cloud field. The difference in the condensed water path between the FSENS and NoHM experiments is $29 \%$ of the water path in the baseline simulation $\left(\left(\mathrm{CWP}(t)_{\max }-\mathrm{CWP}(t)_{\min }\right) / \mathrm{CWP}(t)_{\text {baseline }}\right)$ in the late afternoon ( $\sim$ 15:00-17:00 UTC), but smaller values prevail at other times, resulting in an average maximum spread between the FSENS and NoHM experiments of $14 \%$ (Fig. 6a). In the WARM experiment, the condensed water path is lower than in any other experiment throughout most of the afternoon (maximum of $41 \%$ and mean of $16 \%$ reduction compared with the baseline experiment). This is consistent with the smaller condensate generation and enhanced precipitation efficiency diagnosed for this experiment. Changes in the cloud fraction between the different experiments amount to a maximum of $20 \%$ of the value in the baseline experiment (Fig. 6b). The cloud fraction is defined as the areal fraction of the domain with a column-integrated condensed water path larger than $1 \mathrm{~g} \mathrm{~m}^{-2}$. Again, the maximum differences occur in the late afternoon hours. Averaged over the entire time period, the changes are much smaller $(7 \%)$.

Finally, we also consider the sensitivity of outgoing shortwave and long-wave radiation (Fig. 7). The maximum domain mean difference between any two FSENS and NoHM experiments is about $6 \mathrm{~W} \mathrm{~m}^{-2}$ for the short-wave component and $0.5 \mathrm{~W} \mathrm{~m}^{-2}$ for the long-wave component. The average over the considered time period amounts to $2.9 \mathrm{~W} \mathrm{~m}^{-2}$ $\left(0.27 \mathrm{~W} \mathrm{~m}^{-2}\right)$ for the short-wave (long-wave) component. Similar to the other cloud field characteristics discussed thus far, the largest change occurs in the WARM experiment with a maximum (average) increase of $15 \mathrm{~W} \mathrm{~m}^{-2}\left(5.7 \mathrm{~W} \mathrm{~m}^{-2}\right)$ in the short-wave component and a maximum (average) decrease of $1.4 \mathrm{~W} \mathrm{~m}^{-2}\left(0.5 \mathrm{~W} \mathrm{~m}^{-2}\right)$ in the long-wave component.

Considering the temporal evolution of most cloud properties, i.e. domain-integrated precipitation (not shown), condensed water path (Fig. 6b), and top-of-the-atmosphere outgoing radiation (Fig. 7), the consistency in the evolution be- tween different experiments is noteworthy, which strongly suggests that the COPE clouds are strongly dynamically forced with little leeway for cloud microphysics to change the overall characteristics of the cloud field.

Overall, the sensitivity to the representation of ice formation found here for moderately deep convective clouds (cloud top $\sim-18^{\circ} \mathrm{C}$ ) is smaller than that reported for tropical deep convective clouds (e.g. Hawker et al., 2020). Hawker et al. (2020) found differences of up to $21 \mathrm{~W} \mathrm{~m}^{-2}$ in the total outgoing radiation in a set of simulations comparable to our FSENS experiments. The majority of the signal reported in Hawker et al. (2020) is due to changes in anvil properties. This likely explains the smaller signal in our simulations, as the investigated convective clouds are shallower and do not produce spatially extensive anvil clouds. In particular, in the context of numerical weather prediction as well as for deriving observational constraints on the cloud microphysical parameterizations, it is important to understand how these sensitivities compare to uncertainty in modelled cloud field properties due to other factors such as initial condition uncertainty or uncertainties in the formulation of other model components. To provide some context for the sensitivities discussed here, we compare them in the next section with the spread of a 10-member high-resolution initial condition ensemble.

\section{Comparison to the sensitivity to initial condition perturbations}

The representation of ice formation has a fairly strong impact on the cloud microphysical properties of clouds and can induce changes of between $5 \%$ and $20 \%$ in cloud field properties, such as accumulated precipitation, cloud fraction, and outgoing radiation fluxes (see Sect. 3, summarized in Table 1 in terms of the relative spread). In order to judge the significance of these variations, it is necessary to put them into the context of other uncertainty sources for the modelled cloud properties. As forecasts of convective situations often have a low intrinsic predictability (e.g. Hohenegger and Schär, 2007), it is particularly interesting to use ensemble simulations with perturbed initial conditions as context for sensitivity experiments regarding the model formulation. Here, we use high-resolution ensemble simulations for the COPE case, which were already used by Miltenberger et al. (2018b) to provide context for sensitivity experiments regarding the background aerosol concentration. We focus here on comparing the spread of variables between the ensemble members to the spread between different sensitivity runs. The spread from ensemble runs is indicated in all figures by the grey shaded area.

Altering the representation of ice formation impacts the hydrometeor number, particularly that of ice crystals (ICNC) and cloud droplets (CDNC) in the upper layers (above $\gtrsim 4.5$ and $\gtrsim 3 \mathrm{~km}$ respectively). These changes are much 
(a) DM10

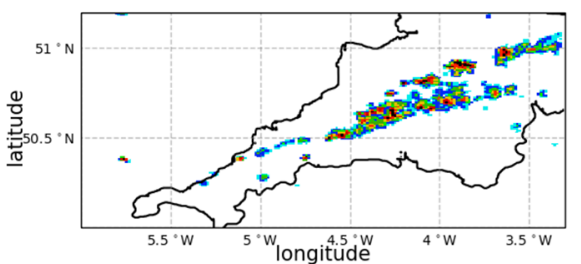

(d) DM15

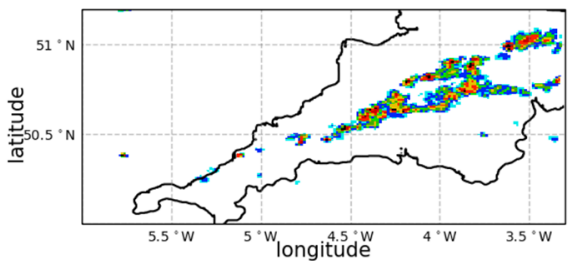

(g) Meyers

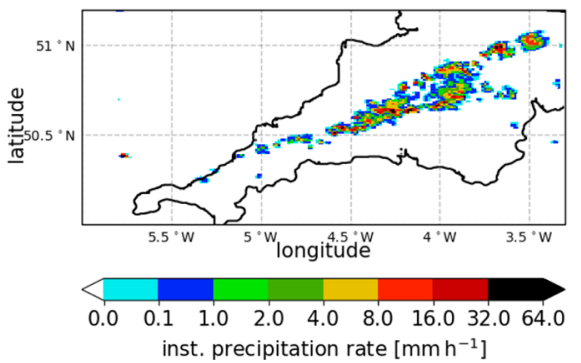

(b) $0.1 \cdot \mathrm{DM} 10$

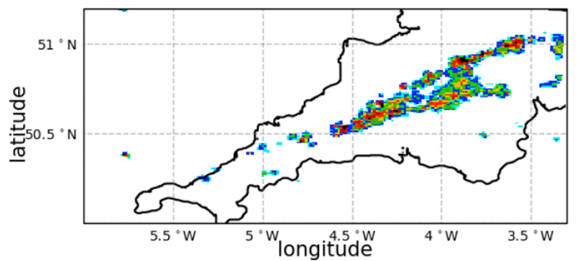

(e) A13

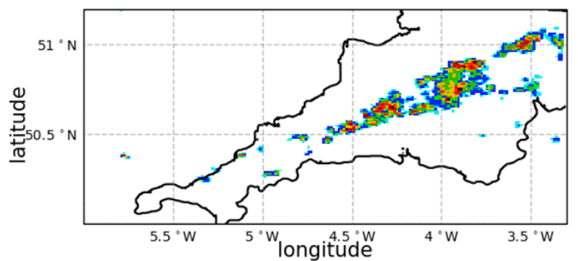

(h) NoHM

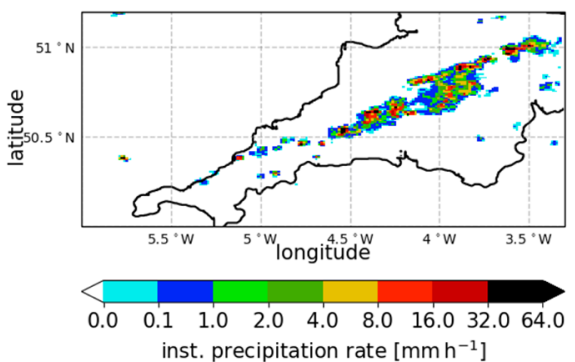

(c) $10 \cdot \mathrm{DM} 10$

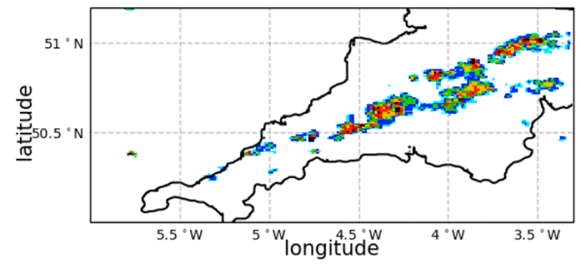

(f) $\mathrm{N} 12$

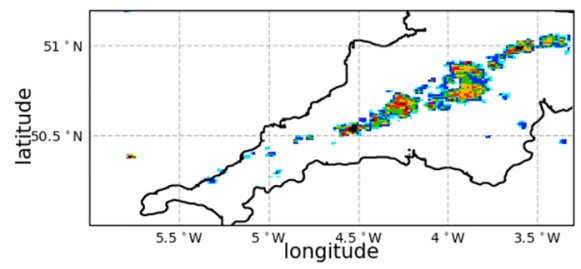

(i) WARM

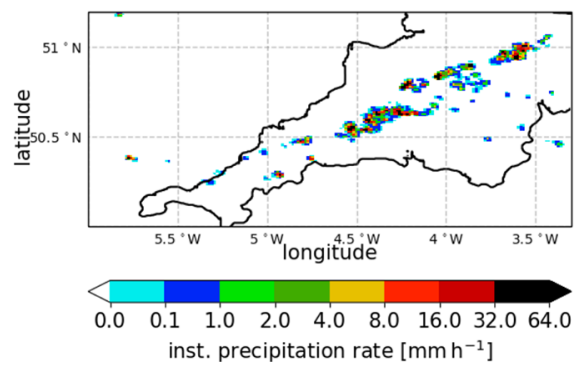

Figure 3. Instantaneous precipitation rate at 14:00 UTC in the different model simulations. Panels (a)-(c) show simulations using the DeMott et al. (2010) parameterization, multiplied by factors 1, 0.1, and 10 respectively. The simulation in panel (a) corresponds to the "baseline" simulation. Panels (d)-(g) show simulations using the parameterizations by DeMott et al. (2015), Atkinson et al. (2013), Niemand et al. (2012), and Meyers et al. (1992). Panel (h) shows the simulation with the DeMott et al. (2010) parameterization but without a parameterization of the Hallett-Mossop processes. Panel (i) shows the simulation without any representation of ice formation.

(a)

(b)
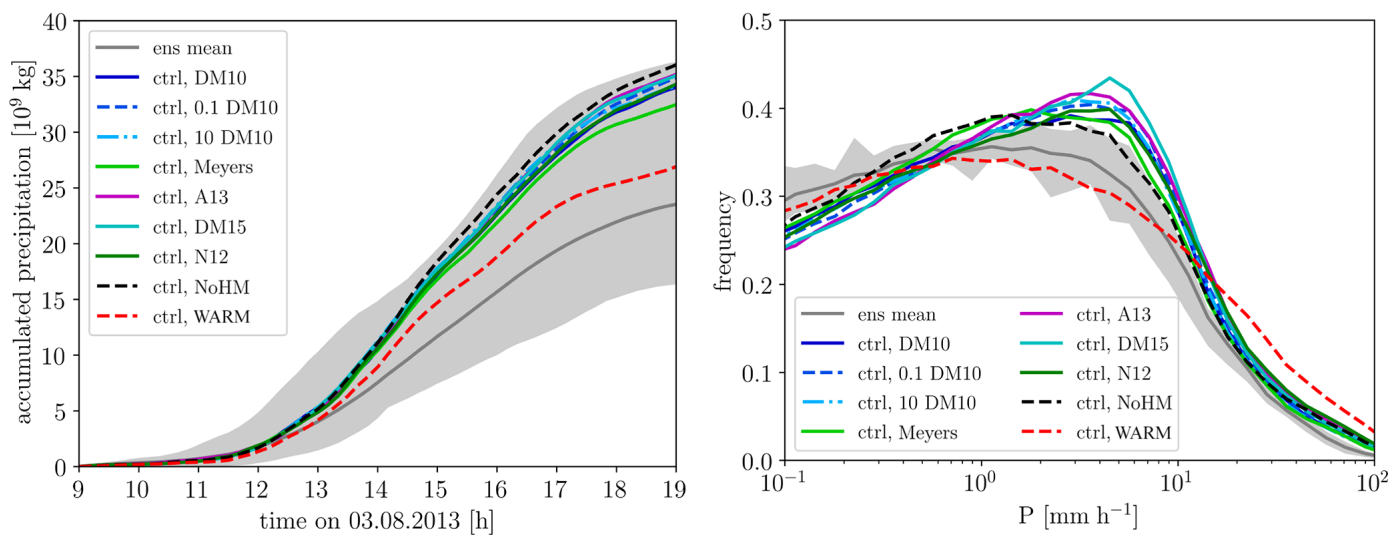

Figure 4. (a) Time series of accumulated surface precipitation. (b) Precipitation rate distribution (excluding non-raining grid points). The dark grey shading shows the spread of the 10 ensemble members with perturbed initial conditions. The grey line represents the ensemble mean, and the various coloured lines represent simulations with different heterogeneous freezing parameterization, pure warm-phase microphysics, and no Hallett-Mossop process (colours according to the legend). 
(a)

(b)
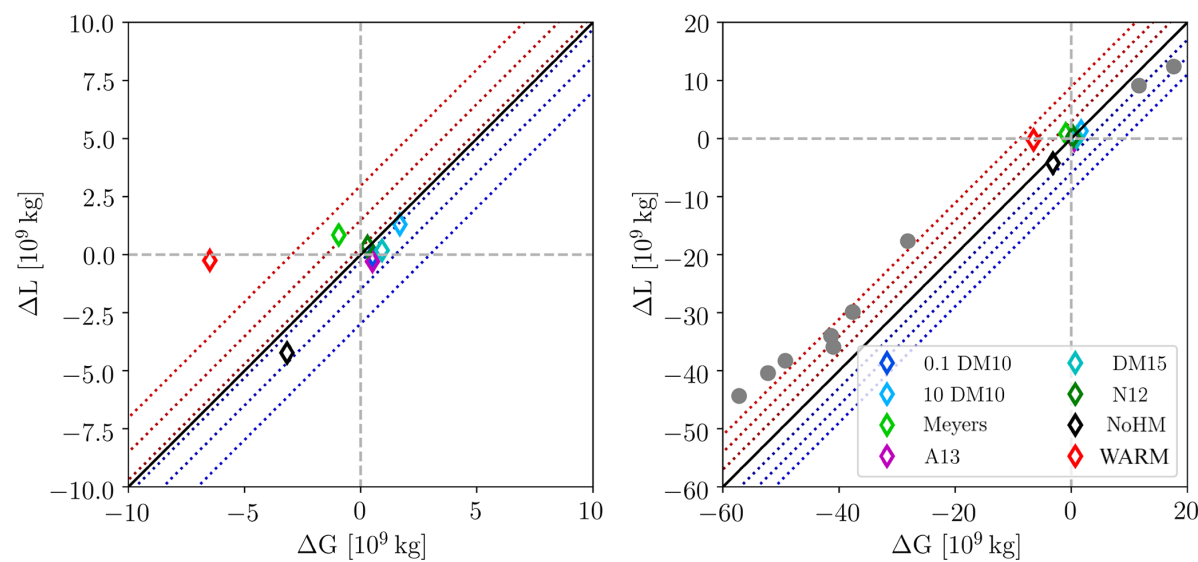

Figure 5. Scatterplot of change in condensate gain $\Delta G$ and condensate loss $\Delta L$ relative to the simulation with the DeMott et al. (2010) heterogeneous freezing parameterization and a representation of the Hallett-Mossop process (baseline simulation). The condensate gain in the baseline simulation is $137.0 \times 10^{9} \mathrm{~kg}$, and the condensate loss is $107.3 \times 10^{9} \mathrm{~kg}$. The grey symbols in panel $(\mathbf{b})$ represent the nine meteorological ensemble members other than the baseline simulation. The blue and red dashed lines indicate relative changes in precipitation of $0.1 \%, 5 \%$, and $10 \%$ in panel (a) and $10 \%, 20 \%$, and $30 \%$ in panel (b)

(a)

(b)
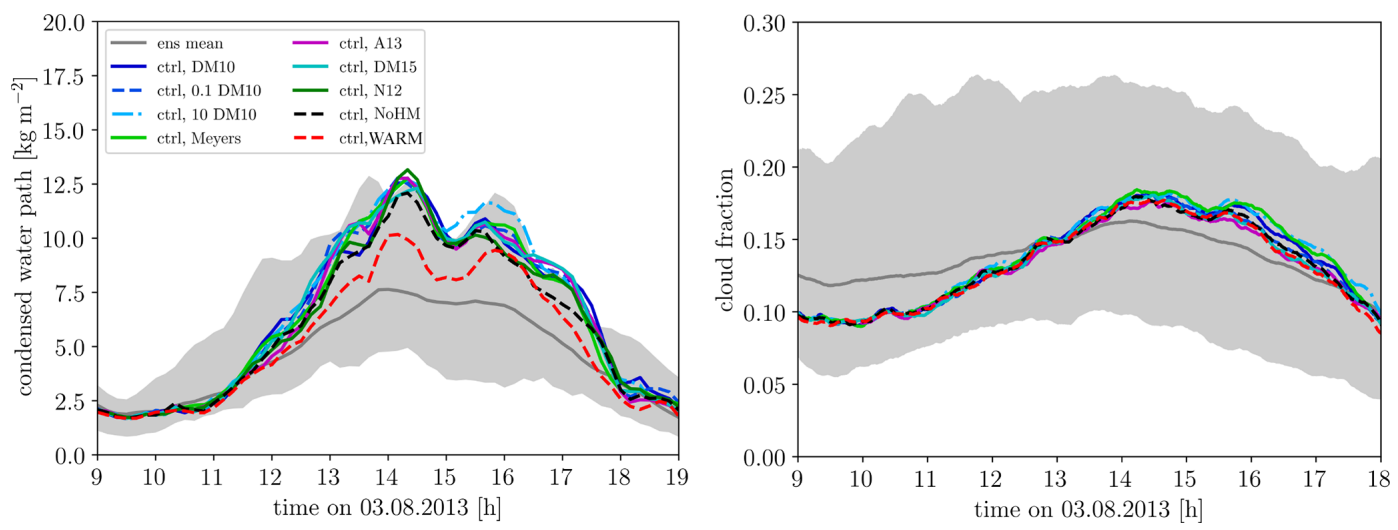

Figure 6. Time series of (a) the average condensed water path and (b) the cloud fraction. The dark grey shading in both panels shows the spread of the 10 ensemble members with perturbed initial conditions. The grey line represents the ensemble mean, and the various coloured lines represent simulations with different heterogeneous freezing parameterization, pure warm-phase microphysics, and no Hallett-Mossop process (colours according to legend).

larger than the maximum spread in mean hydrometeor number profiles from the ensemble (Fig. 1a, c). In contrast, the sensitivity of rain and graupel number densities to different ice formation representations (FSENS) is comparable to the sensitivity of the modelled clouds to perturbations in the initial conditions (Fig. 1b, e). For snow, changes in number concentration across FSENS experiments are clearly smaller than the impact of perturbed initial conditions. Regarding the impact of secondary ice formation, here in the form of the Hallett-Mossop process, it is intriguing to note that the NoHM experiments yield mean hydrometeor profiles that are clearly outside of the ensemble spread for all frozen hydrometeor species.
In general, the picture is very similar when hydrometeor mass mixing ratios are considered instead of their number densities (Fig. 2). The sensitivity to the ice formation representation is larger than the initial condition ensemble spread for upper-level cloud droplet and ice crystal content as well as for the rain water content. The NoHM experiments again have profiles outside the range from the ensemble for all hydrometeor species but with a smaller separation from the ensemble for snow and graupel compared to the number concentration profiles (Fig. 2d, e). Overall, it appears that the sensitivity to ice formation representation is larger than that to initial condition perturbations, even for the mean hydrometeor profiles. 
(a)

(b)
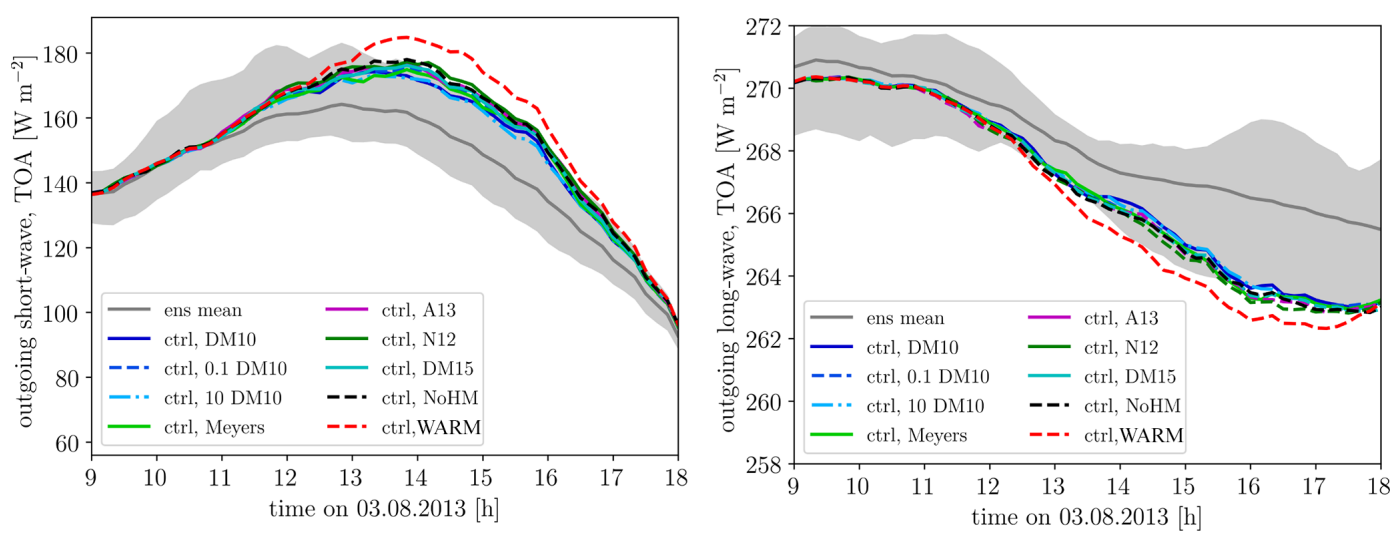

Figure 7. Domain-average time series of outgoing (a) short-wave and (b) long-wave radiation at the top of the atmosphere. The dark grey shading shows the spread of the 10 ensemble members with perturbed initial conditions. The grey line represents the ensemble mean, and the various coloured lines represent simulations with different heterogeneous freezing parameterization, pure warm-phase microphysics, and no Hallett-Mossop process.

Table 1. Relative spread (i.e. difference between maximum and minimum value in any simulation divided by the value in the base line simulation) for mean cloud droplet number concentration (CDNC), ice crystal number concentration (ICNC), cloud mass mixing ratio $\left(q_{\mathrm{c}}\right)$, frozen hydrometeor mass mixing ratio $\left(q_{\mathrm{f}}\right)$, accumulated surface precipitation $(P)$, condensed water path (TWP), cloud fraction, and outgoing short-wave (OSR) and long-wave (OLR) radiation.

\begin{tabular}{lrrrrr}
\hline Variable & $\begin{array}{r}\text { Ensemble } \\
(\mathrm{max}-\mathrm{min})\end{array}$ & $\begin{array}{r}\text { FSENS } \\
(\mathrm{max}-\mathrm{min})\end{array}$ & $\begin{array}{r}\text { FSENS }- \\
\text { DM10 } \\
(\max -\min )\end{array}$ & $\begin{array}{r}\text { Baseline }- \\
\text { NoHM }\end{array}$ & $\begin{array}{r}\text { Baseline - } \\
\text { WARM }\end{array}$ \\
\hline CDNC $(4.5 \mathrm{~km})$ & 1.40 & 2.98 & 0.671 & 0.814 & 7.84 \\
ICNC $(>4.5 \mathrm{~km})$ & 0.961 & 3.36 & 3.19 & 0.503 & - \\
ICNC $(<4.5 \mathrm{~km})$ & 0.439 & 1.29 & 0.969 & 0.876 & - \\
$q_{\mathrm{c}}(>4.5 \mathrm{~km})$ & 5.15 & 5.58 & 0.862 & 2.19 & 12.9 \\
$q_{\mathrm{f}}(>4.5 \mathrm{~km})$ & 2.72 & 0.601 & 0.373 & 0.595 & - \\
$q_{\mathrm{f}}(<4.5 \mathrm{~km})$ & 0.520 & 0.196 & 0.120 & 0.472 & - \\
$P$ & 0.587 & 0.0798 & 0.0254 & 0.0594 & 0.209 \\
TWP & 0.941 & 0.140 & 0.0890 & 0.0775 & 0.159 \\
Cloud fraction & 1.32 & 0.0643 & 0.0404 & 0.0246 & 0.0375 \\
OSR & 0.154 & 0.0190 & 0.00948 & 0.0119 & 0.0321 \\
OLR & & 0.0141 & 0.00102 & 0.000523 & 0.00188 \\
\hline
\end{tabular}

If instead of the cloud microphysical structure the properties of the cloud field are considered, the picture changes: considering, for example, the accumulated surface precipitation, the differences between the FSENS and NoHM experiments are only very small if compared to the spread between members in the initial condition ensemble (Fig. 4a). The ratio between the spread from the sensitivity experiments (FSENS and NoHM) and the spread from the ensemble is roughly 0.2 . Even the difference between the baseline and the WARM experiments is much smaller than the ensemble spread. Unsurprisingly, the differences in the condensate budget are also much larger across the initial condition ensemble compared with the sensitivity experiments (Fig. 5b). However, if precipitation efficiency is considered, the variability across ensemble members $(0.176-0.256)$ and sensi- tivity experiments $(0.180-0.230)$ is again very similar (not shown). This suggests that the dominance of initial condition uncertainty for the accumulated precipitation is due to the strong control of larger-scale moisture and moist static energy convergence. For the conversion of this condensate to precipitation, however, the representation of cloud microphysical processes is at least as important as the larger-scale meteorological conditions. In the investigated case, variability in condensate generation clearly exceeds the impact of the variability in precipitation efficiency; hence, the former dominates the predicted spread of accumulated precipitation.

Similar to accumulated precipitation, the spread between ensemble members is much larger for condensed water path, cloud fraction, and short-wave and long-wave outgoing radiation than their sensitivity to a particular representation of 
ice formation (Figs. 6,7). The relative spread between various sensitivity experiments and ensemble members is summarized in Table 1.

Our analysis suggests that, at least for the investigated case, forecast uncertainty is dominated by initial condition uncertainty for all cloud field variables, whereas uncertainty intrinsic to the representation of ice formation (reflected by parameterization choice) only plays a dominant role for the detailed cloud microphysical structure.

\section{Discussion and conclusions}

We investigate the sensitivity of model predictions of a moderately deep convective cloud field to altered representations of ice formation (different heterogeneous freezing parameterizations, representation of Hallett-Mossop process) and to initial condition uncertainty for lead times of up to $19 \mathrm{~h}$. The investigated case was selected from those observed in the COPE campaign (e.g. Leon et al., 2016). The case has already been investigated in Miltenberger et al. $(2018 \mathrm{a}, \mathrm{b})$ with a focus on aerosol-cloud interactions.

Altering the ice formation representation impacts the cloud microphysical structure, in particular the cloud droplet, ice crystal, and graupel mass mixing ratio and number concentration, as well as cloud field properties such as surface precipitation, cloud fraction, and outgoing short-wave and long-wave radiation. Accumulated surface precipitation varies by about $8 \%(21 \%)$ and the mean cloud fraction varies by about $7 \%(7 \%)$ across experiments with different descriptions of ice formation (only warm-phase cloud microphysics). Average outgoing short-wave radiation changes by $2.9 \mathrm{~W} \mathrm{~m}^{-2}\left(2.9 \mathrm{~W} \mathrm{~m}^{-2}\right)$ and outgoing long-wave radiation changes by $1.4 \mathrm{~W} \mathrm{~m}^{-2}\left(0.5 \mathrm{~W} \mathrm{~m}^{-2}\right)$ in the respective set of experiments. The sensitivity to the representation of ice formation in our case is smaller than the sensitivity found by Hawker et al. (2020) for tropical deep convective clouds. In Hawker et al. (2020), the anvils of convective clouds contributed significantly to the overall changes in cloud fraction and outgoing radiation components. In contrast to their case, cloud in our case only reaches up to a stable layer in the mid-troposphere (Miltenberger et al., 2018a) and no anvils are present. This likely explains the smaller sensitivity to the representation of ice formation.

The importance of the observed sensitivity to ice formation representation for numerical weather forecasting depends on how it compares to other sources of uncertainty for predicting the cloud field evolution, including initial condition uncertainty and parametric or systematic uncertainty in other model components. In the present work, we use a highresolution initial condition ensemble to provide context for the sensitivity experiments. When comparing the ensemble spread to the differences between sensitivity experiments, it becomes clear that for bulk cloud field properties, such as accumulated precipitation, cloud fraction, and outgoing ra- diation, the initial condition uncertainty clearly exceeds the sensitivity to the formulation of ice formation. However, for the mean hydrometeor profiles, in particular cloud droplet, ice crystal, and graupel mass mixing ratios and number concentration, the initial condition uncertainty is less important than the choice of the ice formation parameterization. The impact of the Hallett-Mossop process is particularly evident, as the mean profiles in simulations without a representation of the Hallett-Mossop processes are clearly outside of the ensemble spread. While this may indicate a significant role of secondary ice formation in this cloud type, the representation of secondary ice formation in clouds is itself highly uncertain, and this uncertainty has not been explored here. The large impact of initial and boundary conditions on the bulk cloud field properties derives from the strong control of moisture and moist static energy convergence on these. Combined with the clearly different cloud microphysical structure of the clouds, this implies that altering the chosen ice formation parameterizations impacts the pathway of precipitation formation, albeit with a small impact on the larger-scale cloud properties, i.e. suggesting the considered mixed-phase cloud systems maintains its large-scale properties regardless of changes in the balance of the microphysical pathways.

It would be interesting to compare the sensitivity to the ice formation parameterization with the impact of other parametric uncertainties in the model. In a previous study, we have investigated the sensitivity of the same case to alterations of the aerosol background concentration (a factor of 10 increase and decreases respectively) (Miltenberger et al., 2018a, b). We found that the cloud field is also less sensitive to changes in aerosol conditions than to perturbations of initial conditions, at least if larger-scale properties such as accumulated precipitation, cloud fraction, and radiative fluxes are considered. In summary, this suggests that COPE-type clouds are strongly controlled by meteorological conditions with comparatively little leeway for cloud microphysics to modify cloud field properties.

Of course the following question arises: is this dominance of initial condition uncertainty a special feature of the chosen case? To date, few studies have combined an ensemble approach with sensitivity experiments (e.g. Seifert et al., 2012), and most of these works have focused on idealized cases (e.g. Grabowski et al., 1999; Morrison, 2012; Wang et al., 2012; Posselt et al., 2019; Wellmann et al., 2020). Nevertheless, the overall findings are compatible with the present study in that bulk properties, such as radiative fluxes and accumulated precipitation, are strongly influenced by larger-scale meteorological conditions and, to a lesser degree, by perturbations to the cloud microphysical scheme - be it perturbations to the aerosol environment (e.g. Seifert et al., 2012; Grabowski et al., 1999; Morrison, 2012) or to the formulation of cloud microphysical processes (e.g. Wang et al., 2012; Posselt et al., 2019; Wellmann et al., 2020). Recently, several studies ventured to systematically investigate the joint impact of multiple uncertain parameters in the cloud microphysics 
representation, although again these studies were largely focused on idealized cases (e.g. Johnson et al., 2015; Glassmeier et al., 2019). For idealized simulations of deep convection, Johnson et al. (2015) found a small impact of parameters in the immersion freezing parameterization on accumulated precipitation compared with the impact of other parameters in the cloud microphysical parameterization, such as collection efficiencies and aerosol number concentration, which is consistent with our COPE studies. In the absence of more studies systematically combining perturbations to aerosol conditions and/or cloud microphysical processes, we can only speculate about the impact of such perturbations beyond initial condition uncertainty. The COPE case represents a convective situation with a fairly strong forcing from the converging sea-breeze fronts and the convergence of moisture into the study area. In cases with a weaker dynamic forcing, such as unorganized convection, we expect a lesser impact of the initial condition uncertainty. However, whether uncertainty in the cloud microphysics representation and, in particular, which cloud microphysical processes will dominate over initial condition uncertainty is difficult to assess a priori. If the changes in the cloud microphysics representation lead to a systematic shift that is consistent in sign across a large range of conditions, this should become clearly visible if a large number of cases are considered. How large such a set of cases needs to be depends on the degree to which large-scale meteorological conditions are constrained as well as on the relative impact of these meteorological conditions and the model perturbations on the variables of interest (for an example concerning an assessment of this for aerosol perturbations in COPE-like scenarios, see Miltenberger et al., 2018b).
In summary, the simulations show that differences in ice formation parameterization primarily impact the cloud microphysical structure with less impact on cloud field properties. Although broadly consistent with previous work, the study presented here has some shortcomings, which we plan to address in future work. Mainly it would be desirable to repeat the full ensemble simulations with the changes to the cloud microphysics representation, to investigate the number of joint parameter perturbations, to test the sensitivity to the choice of the domain (e.g. White et al., 2018), and to repeat the analysis for different cases. 


\section{Appendix A: Additional detail on the model set-up}

The regional simulations used in this paper are run without a convection parameterization and without a cloud scheme. Boundary layer processes are parameterized with the blended boundary layer scheme by Lock et al. (2015) and turbulence with a 3-D Smagorinsky-type turbulence scheme. Radiation fluxes are parameterized with the SOCRATES scheme (Suite of Community RAdiative Transfer codes; Edwards and Slingo, 1996; Manners, 2017). In addition, moisture conservation in the regional domain is enforced using the scheme by Aranami et al. $(2014,2015)$.

Cloud microphysical processes are represented by the CASIM microphysics. The cloud particle population is represented by the mass and number concentration of five hydrometeor categories assuming gamma distributions. In addition, the mass and number concentration of four aerosol modes are computed based on the prescribed initial and lateral boundary conditions as well as advection inside the domain. Droplet activation is parameterized following AbdulRazzak et al. (1998) and Abdul-Razzak and Ghan (2000). Further represented processes include condensational growth by the saturation adjustment scheme, freezing of rain drops (Bigg, 1953), homogeneous freezing of cloud droplets (Jeffery and Austin, 1997), Hallett-Mossop processes, vapour deposition, collision-coalescence processes between all hydrometeors, and gravitational settling of all hydrometeor categories except cloud droplets. For heterogeneous freezing of cloud droplets, different parameterizations are used, as detailed in Sect. 2.
Table A1. Aerosol number concentration $(N)$, mass density $(m)$, and width of the size distribution $(\sigma)$ prescribed as lateral boundary and initial conditions in the boundary layer.

\begin{tabular}{lrrr}
\hline & $\begin{array}{r}N \\
\left(\mathrm{~cm}^{-3}\right)\end{array}$ & $\begin{array}{r}m \\
\left(\mathrm{~kg} \mathrm{~m}^{-3}\right)\end{array}$ & $\begin{array}{c}\sigma \\
(\mathrm{L})\end{array}$ \\
\hline Aitken mode & 860 & $5.86 \times 10^{-10}$ & 2.2 \\
Accumulation mode & 150 & $3.84 \times 10^{-9}$ & 1.7 \\
Coarse mode & 0.23 & $1.07 \times 10^{-8}$ & 1.5 \\
Insoluble mode & 16.7 & $4.26 \times 10^{-10}$ & 1.5 \\
\hline
\end{tabular}

The initial and lateral boundary conditions for aerosols are based on aircraft observations from the COPE campaign. Different aerosol number and mass concentrations are prescribed in the planetary boundary layer and the free troposphere with a linear transition between the two values. The transition zone is centred at $1.15 \mathrm{~km}$ and has a depth of $500 \mathrm{~m}$. The aerosol number and mass concentrations are constant with altitude in the boundary layer and the free troposphere. The values used for the boundary layer are given in Table A1. 
Data availability. Model data are stored on the tape archive provided by JASMIN (http://www.jasmin.ac.uk/, last access: 9 March 2021) (UKRI NERC, 2021a). Access to Met Office data via JASMIN is described at http://www.ceda.ac.uk/blog/ access-to-the-met-office-mass-archive-on-jasmin-goes-live/ (last access: 9 March 2021) (UKRI NERC, 2021b). The data can be made accessible upon reasonable request to the authors.

Supplement. The supplement related to this article is available online at: https://doi.org/10.5194/acp-21-3627-2021-supplement.

Author contributions. AKM and PRF contributed to the development of the concepts and ideas presented in this paper. AKM set up and ran the model simulations, performed the model analysis, and wrote the majority of the paper with input and comments from PRF.

Competing interests. The authors declare that they have no conflict of interest.

Acknowledgements. We thank Adrian Hill, Ben Shipway, and Jonathan Wilkinson for the development of the CASIM module. We acknowledge the use of the Monsoon/NEXCS system, a collaborative facility supplied under the Joint Weather and Climate Research Programme, a strategic partnership between the Met Office and the Natural Environment Research Council. Further, we acknowledge the JASMIN storage facilities (https://doi.org/10.1109/BigData.2013.6691556). The University of Leeds and the Johannes Gutenberg University Mainz are acknowledged for providing funds for this study. We thank three anonymous reviewers for their comments on the paper.

Financial support. This open-access publication was funded by Johannes Gutenberg University Mainz.

Review statement. This paper was edited by Stefano Galmarini and reviewed by three anonymous referees.

\section{References}

Abdul-Razzak, H. and Ghan, S. J.: A parameterization of aerosol activation. 2. Multiple aerosol types, J. Geophys. Res., 105, 68376844, 2000.

Abdul-Razzak, H., Ghan, S. J., and Rivera-Carpio, C.: A parameterization of aerosol activation. 1. Single aerosol type, J. Geophys. Res., 103, 6123-6131, 1998.

Aranami, K., Zerroukat, M., and Wood, N.: Mixing properties of SLICE and other mass-conservative semi-Lagrangian schemes, Q. J. Roy. Meteorol. Soc., 140, 2084-2089, https://doi.org/10.1002/qj.2268, 2014.

Aranami, K., Davies, T., and Wood, N.: A mass restoration scheme for limited-area models with semi-Lagrangian advection, Q. J. Roy. Meteorol. Soc., 141, 1795-1803, https://doi.org/10.1002/qj.2482, 2015.

Atkinson, J. D., Murray, B. J., Woodhouse, M. T., Whale, T. F., Baustian, K. J., Carslaw, K. S., Dobbie, S., O’Sullivan, D., and Malkin, T. L.: The importance of feldspar for ice nucleation by mineral dust in mixed-phase clouds, Nature, 498, 355-358, https://doi.org/10.1038/nature12278, 2013.

Barstad, I., Grabowski, W. W., and Smolarkiewicz, P. K.: Characteristics of large-scale orographic precipitation: Evaluation of linear model in idealized problems, J. Hydrol., 340, 78-90, 2007.

Bigg, E. K.: The formation of atmospheric ice crystals by the freezing of droplets, Q. J. Roy. Meteorol. Soc., 39, 510-519, 1953.

Blyth, A. M., Bennett, L. J., and Collier, C. G.: High-resolution observations of precipitation from cumulonimbus clouds, Meteorol. Appl., 22, 75-89, https://doi.org/10.1002/met.1492, 2015.

Bowler, N. E., Arribas, A., Mylne, K. R., Robertson, K. B., and Beare, S. E.: The MOGREPS short-range ensemble prediction system, Q. J. Roy. Meteorol. Soc., 134, 703-722, https://doi.org/10.1002/qj.234, 2008

Cooper, W. A.: Ice Initiation in Natural Clouds, American Meteorological Society, Boston, MA, 29-32, https://doi.org/10.1007/978-1-935704-17-1_4, 1986.

DeMott, P. J., Prenni, A. J., Liu, X., Kreidenweis, S. M., Petters, M. D., Twohy, C. H., Richardson, M. S., Eidhammer, T., and Rogers, D. C.: Predicting global atmospheric ice nuclei distributions and their impacts on climate, P. Natl. Acad. Sci. USA, 107, 1121711222, https://doi.org/10.1073/pnas.0910818107, 2010.

DeMott, P. J., Prenni, A. J., McMeeking, G. R., Sullivan, R. C., Petters, M. D., Tobo, Y., Niemand, M., Möhler, O., Snider, J. R., Wang, Z., and Kreidenweis, S. M.: Integrating laboratory and field data to quantify the immersion freezing ice nucleation activity of mineral dust particles, Atmos. Chem. Phys., 15, 393-409, https://doi.org/10.5194/acp-15-393-2015, 2015.

Dey, S. R. A., Leoncini, G., Roberts, N. M., Plant, R. S., and Migliorini, S.: A spatial view of ensemble spread in convection permitting ensembles, Mon. Weather Rev., 142, 4091-4107, https://doi.org/10.1175/MWR-D-14-00172.1, 2014.

Edwards, J. M. and Slingo, A.: Studies with a flexible new radiation code. I: Choosing a configuration for a largescale model, Q. J. Roy. Meteorol. Soc., 122, 689-719, https://doi.org/10.1002/qj.49712253107, 1996.

Field, P. R. and Furtado, K.: How Biased Is Aircraft Cloud Sampling?, J. Atmos. Ocean. Tech., 33, 185-189, https://doi.org/10.1175/JTECH-D-15-0148.1, 2016.

Field, P. R. and Heymsfield, A. J.: Importance of snow to global precipitation, Geophys. Res. Lett., 42, 9512-9520, https://doi.org/10.1002/2015GL065497, 2015.

Field, P. R., Lawson, R. P., Brown, P. R. A., Lloyd, G., Westbrook, C., Moisseev, D., Miltenberger, A., Nenes, A., Blyth, A., Choularton, T., Connolly, P., Buehl, J., Crosier, J., Cui, Z., Dearden, C., DeMott, P., Flossmann, A., Heymsfield, A., Huang, Y., Kalesse, H., Kanji, Z. A., Korolev, A., Kirchgaessner, A., LasherTrapp, S., Leisner, T., McFarquhar, G., Phillips, V., Stith, J., and Sullivan, S.: Secondary Ice Production: Current State of the Science and Recommendations for the Future, Meteorol. Monogr., 58, 7.1-7.20, https://doi.org/10.1175/AMSMONOGRAPHS-D16-0014.1, 2017.

Glassmeier, F., Hoffmann, F., Johnson, J. S., Yamaguchi, T., Carslaw, K. S., and Feingold, G.: An emulator approach to 
stratocumulus susceptibility, Atmos. Chem. Phys., 19, 1019110203, https://doi.org/10.5194/acp-19-10191-2019, 2019.

Grabowski, W. W., Wu, X., and Moncrieff, M. W.: Cloud Resolving Modeling of Tropical Cloud Systems during Phase III of GATE. Part III: Effects of Cloud Microphysics, J. Atmos. Sci., 56, 2384-2402, https://doi.org/10.1175/15200469(1999)056<2384:CRMOTC>2.0.CO;2, 1999.

Harrison, D. L., Scovell, R. W., and Kitchen, M.: Highresolution precipitation estimates for hydrological uses, P. Inst. Civ. Eng.-Water Manage., 162, 125-135, https://doi.org/10.1680/wama.2009.162.2.125, 2009.

Hawker, R. E., Miltenberger, A. K., Wilkinson, J. M., Hill, A. A., Shipway, B. J., Cui, Z., Cotton, R. J., Carslaw, K. S., Field, P. R., and Murray, B. J.: The nature of ice-nucleating particles affects the radiative properties of tropical convective cloud systems, Atmos. Chem. Phys. Discuss. [preprint], https://doi.org/10.5194/acp-2020-571, in review, 2020.

Hohenegger, C. and Schär, C.: Predictability and error growth dynamics in cloud-resolving models, J. Atmos. Sci., 64, 44674478, https://doi.org/10.1175/2007JAS2143.1, 2007.

Jeffery, C. A. and Austin, P. H.: Homogeneous nucleation of supercooled water: Results from a new equation of state, J. Geophys. Res.-Atmos., 102, 25269-25279, https://doi.org/10.1029/97JD02243, 1997.

Johnson, J. S., Cui, Z., Lee, L. A., Gosling, J. P., Blyth, A. M., and Carslaw, K. S.: Evaluating uncertainty in convective cloud microphysics using statistical emulation, J. Adv. Model. Earth Syst., 7, 162-187, https://doi.org/10.1002/2014MS000383, 2015.

Khain, A. P.: Notes on state-of-the-art investigations of aerosol effects on precipitation: A critical review, Environ. Res. Lett., 4, 015004, https://doi.org/10.1088/1748-9326/4/1/015004, 2009.

Klein, S. A., McCoy, R. B., Morrison, H., Ackerman, A. S., Avramov, A., d. Boer, G., Chen, M., Cole, J. N. S., Del Genio, A. D., Falk, M., Foster, M. J., Fridlind, A., Golaz, J.-C., Hashino, T., Harrington, J. Y., Hoose, C., Khairoutdinov, M. F., Larson, V. E., Liu, X., Luo, Y., McFarquhar, G. M., Menon, S., Neggers, R. A. J., Park, S., Poellot, M. R., Schmidt, J. M., Sednev, I., Shipway, B. J., Shupe, M. D., Spangenberg, D. A., Sud, Y. C., Turner, D. D., Veron, D. E., v. Salzen, K., Walker, G. K., Wang, Z., Wolf, A. B., Xie, S., Xu, K.-M., Yang, F., and Zhang, G.: Intercomparison of model simulations of mixed-phase clouds observed during the ARM Mixed-Phase Arctic Cloud Experiment. I: single-layer cloud, Q. J. Roy. Meteorol. Soc., 135, 979-1002, https://doi.org/10.1002/qj.416, 2009.

Korolev, A., McFarquhar, G., Field, P. R., Franklin, C., Lawson, P., Wang, Z., Williams, E., Abel, S. J., Axisa, D., Borrmann, S., Crosier, J., Fugal, J., Krämer, M., Lohmann, U., Schlenczek, O., Schnaiter, M., and Wendisch, M.: Mixedphase clouds: Progress and challenges, Meteorol. Monogr., 58, 5.1-5.50, https://doi.org/10.1175/AMSMONOGRAPHS-D17-0001.1, 2017.

Leon, D. C., French, J. R., Lasher-Trapp, S., Blyth, A. M., Abel, S. J., Ballard, S., Barrett, A., Bennett, L. J., Bower, K., Brooks, B., Brown, P., Charlton-Perez, C., Choularton, T., Clark, P., Collier, C., Crosier, J., Cui, Z., Dey, S., Dufton, D., Eagle, C., Flynn, M. J., Gallagher, M., Halliwell, C., Hanley, K., HawknessSmith, L., Huang, Y., Kelly, G., Kitchen, M., Korolev, A., Lean, H., Liu, Z., Marsham, J., Moser, D., Nicol, J., Norton, E. G., Plummer, D., Price, J., Ricketts, H., Roberts, N., Rosenberg, P.
D., Simonin, D., Taylor, J. W., Warren, R., Williams, P. I., and Young, G.: The Convective Precipitation Experiment (COPE): Investigating the origins of heavy precipitation in the Southwestern United Kingdom, B. Am. Meteorol. Soc., 97, 1003-1020, https://doi.org/10.1175/BAMS-D-14-00157.1, 2016.

Levin, Z., Teller, A., Ganor, E., and Yin, Y.: On the interactions of mineral dust, sea-salt particles, and clouds: A measurement and modeling study from the Mediterranean Israeli Dust Experiment campaign, J. Geophys. Res.-Atmos., 110, D20202, https://doi.org/10.1029/2005JD005810, 2005.

Lock, A., Edwards, J., and Boutle, I.: The parameterisation of boundary layer processes, Unified model documentation paper 024, Met Office, Exeter, 2015.

Lohmann, U. and Hoose, C.: Sensitivity studies of different aerosol indirect effects in mixed-phase clouds, Atmos. Chem. Phys., 9, 8917-8934, https://doi.org/10.5194/acp-9-8917-2009, 2009.

Manners, J.: The radiation code, Unified model documentation paper 023, Met Office, Exeter, 2017.

McCoy, D. T., Tan, I., Hartmann, D. L., Zelinka, M. D., and Storelvmo, T.: On the relationships among cloud cover, mixed-phase partitioning, and planetary albedo in GCMs, J. Adv. Model. Earth Syst., 8, 650-668, https://doi.org/10.1002/2015MS000589, 2016.

Meyers, M. P., DeMott, P. J., and Cotton, W. R.: New primary icenucleation parameterizations in an explicit cloud model, J. Appl Meteorol., 31, 708-721, 1992.

Miltenberger, A. K.: Lagrangian perspective on dynamic and microphysical processes in orographically forced flows, $\mathrm{PhD}$ thesis, ETH Zurich, Zurich, https://doi.org/10.3929/ethz-a-010406950, 2014.

Miltenberger, A. K., Field, P. R., Hill, A. A., Rosenberg, P., Shipway, B. J., Wilkinson, J. M., Scovell, R., and Blyth, A. M.: Aerosol-cloud interactions in mixed-phase convective clouds Part 1: Aerosol perturbations, Atmos. Chem. Phys., 18, 31193145, https://doi.org/10.5194/acp-18-3119-2018, 2018a.

Miltenberger, A. K., Field, P. R., Hill, A. A., Shipway, B. J., and Wilkinson, J. M.: Aerosol-cloud interactions in mixed-phase convective clouds - Part 2: Meteorological ensemble, Atmos. Chem. Phys., 18, 10593-10613, https://doi.org/10.5194/acp-1810593-2018, 2018b.

Morrison, H.: On the robustness of aerosol effects on an idealized supercell storm simulated with a cloud systemresolving model, Atmos. Chem. Phys., 12, 7689-7705, https://doi.org/10.5194/acp-12-7689-2012, 2012.

Niemand, M., Möhler, O., Vogel, B., Vogel, H., Hoose, C., Connolly, P., Klein, H., Bingemer, H., DeMott, P., Skrotzki, J., and Leisner, T.: A particle-surface-area-based parameterization of immersion freezing on desert dust particles, J. Atmos. Sci., 69, 3077-3092, https://doi.org/10.1175/JAS-D-11-0249.1, 2012.

Posselt, D. J., He, F., Bukowski, J., and Reid, J. S.: On the Relative Sensitivity of a Tropical Deep Convective Storm to Changes in Environment and Cloud Microphysical Parameters, J. Atmos. Sci., 76, 1163-1185, https://doi.org/10.1175/JAS-D-18-0181.1, 2019.

Seifert, A., Köhler, C., and Beheng, K. D.: Aerosol-cloudprecipitation effects over Germany as simulated by a convectivescale numerical weather prediction model, Atmos. Chem. Phys. 12, 709-725, https://doi.org/10.5194/acp-12-709-2012, 2012. 
Sullivan, S. C., Hoose, C., Kiselev, A., Leisner, T., and Nenes, A.: Initiation of secondary ice production in clouds, Atmos. Chem. Phys., 18, 1593-1610, https://doi.org/10.5194/acp-181593-2018, 2018.

UKRI NERC - UKRI Science and Technology Facilities Council: jasmin webpage, available at: http://www.jasmin.ac.uk/ (last access: 9 March 2021), 2021a.

UKRI NERC - UKRI Science and Technology Facilities Council: Webpage of Centre for Environmental data analysis (NERC), available at: http://www.ceda.ac.uk/blog/ access-to-the-met-office-mass-archive-on-jasmin-goes-live/ (last access: 9 March 2021), 2021 b.

Vergara-Temprado, J., Miltenberger, A. K., Furtado, K., Grosvenor, D. P., Shipway, B. J., Hill, A. A., Wilkinson, J. M., Field, P. R., Murray, B. J., and Carslaw, K. S.: Strong control of Southern Ocean cloud reflectivity by icenucleating particles, P. Natl. Acad. Sci. USA, 115, 2687-2692, https://doi.org/10.1073/pnas.1721627115, 2018.

Wang, H., Auligné, T., and Morrison, H.: Impact of Microphysics Scheme Complexity on the Propagation of Initial Perturbations, Mon. Weather Rev., 140, 2287-2296, https://doi.org/10.1175/MWR-D-12-00005.1, 2012.
Wellmann, C., Barrett, A. I., Johnson, J. S., Kunz, M., Vogel, B., Carslaw, K. S., and Hoose, C.: Comparing the impact of environmental conditions and microphysics on the forecast uncertainty of deep convective clouds and hail, Atmos. Chem. Phys., 20, 2201-2219, https://doi.org/10.5194/acp-20-2201-2020, 2020.

White, B. A., Buchanan, A. M., Birch, C. E., Stier, P., and Pearson, K. J.: Quantifying the Effects of Horizontal Grid Length and Parameterized Convection on the Degree of Convective Organization Using a Metric of the Potential for Convective Interaction, J. Atmos. Sci., 75, 425-450, https://doi.org/10.1175/JAS-D-160307.1, 2018.

Wilson, T. W., Ladino, L. A., Alpert, P. A., Breckels, M. N., Brooks, I. M., Browse, J., Burrows, S. M., Carslaw, K. S., Huffman, J. A., Judd, C., Kilthau, W. P., Mason, R. H., McFiggans, G., Miller, L. A., Nájera, J. J., Polishchuk, E., Rae, S., Schiller, C. L., Si, M., Temprado, J. V., Whale, T. F., Wong, J. P. S., Wurl, O., Yakobi-Hancock, J. D., Abbatt, J. P. D., Aller, J. Y., Bertram, A. K., Knopf, D. A., and Murray, B. J.: A marine biogenic source of atmospheric ice-nucleating particles, Nature, 525, 234-238, https://doi.org/10.1038/nature14986, 2015. 